\title{
APUNTES SOBRE LA AUTOTRADUCCIÓN CATALANA CONTEMPORÁNEA
}

Pilar Arnau i Segarra Universitat de les Illes Balears parnausegarra@gmail.com

RESUMEN: La autotraducción literaria catalana no es un fenómeno nuevo pero se ha intensificado desde 1975. Actualmente muchos escritores catalanes que escriben literatura de ficción en catalán deciden traducir ellos mismos sus obras al castellano. Los motivos que generan estas autotraducciones son muy diversos. En muchos casos el resultado de las autotraducciones catalanas va más allá del ejercicio de la autotraducción y se convierte en un proceso de reescritura literaria en lengua castellana.

PALABRAS CLAVE: autotraducción; escritores bilingües; autotraducción unidireccional; literatura catalana contemporánea

ABSTRACT: Self-Translation of literary works is not a new phenomenon but has intensified since 1975. Currently many Catalan writers who write fiction in Catalan decide to translate their works into Castilian themselves. Their reasons for doing so are very diverse. In many cases what begins as a translation by the author of a piece of writing in Catalan actually goes beyond that and results in a process of rewriting the work in Castilian Spanish.

KEYWORDS: Self-translation; Bilingual Writers; Unidirectional Translation by Author; Catalan Writers; Contemporary Catalan Literature

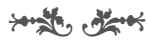




\section{INTRODUCCIÓN}

La autotraducción literaria no es un fenómeno conocido y divulgado culturalmente en nuestra sociedad. Se suele adjudicar al escritor catalán Eduardo Mendoza (Barcelona 1943) una frase lapidaria que hace alarde de la casi inexistencia de los autotraductores: "podríamos contarlos con los dedos de una mano", exclamaba Mendoza en un congreso de traducción (Recuenco Peñalver 2011: 194). Sin embargo, si consultamos diversos estudios de Julio César Santoyo $(2002,2010)$ percibimos que Mendoza no estaba en lo cierto. ${ }^{1}$ La historia de la autotraducción catalana cuenta con exponentes tan notables como el mismísimo Ramon Llull (1232-1315), de quien actualmente estamos conmemorando el séptimo centenario de su muerte con numerosos actos en su tierra natal, la isla de Mallorca -especialmente en Palma-, pero también en las ciudades de Barcelona y Valencia.

Llull fue un sabio sin parangón en las culturas occidentales. Autor de obras magnas en catalán, latín, árabe y provenzal, fue probablemente el autotraductor más prolífico de la Edad Media europea (Recuenco Peñalver 2011: 194). Llull, como otros sabios de su época, se hallaba en un cruce de lenguas y culturas muy diferentes que se materializaban especialmente en la escolástica, el mundo árabe y la poesía trovadoresca. Su afán por cristianizar le llevó a traducir textos religiosos muy diversos, propios y ajenos. Así fue como, por un lado, Llull, al traducir textos al árabe, contribuyó a propagar la religión cristiana entre quienes no la profesaban, especialmente entre los musulmanes de la cuenca mediterránea. Y, por otro lado, con la aparición de una nueva clase de lectores, alejados de las esferas eclesiásticas latinistas, Llull tradujo y compuso muchos textos en lengua vernácula, convirtiéndose así en uno de los mayores forjadores de la lengua catalana. La labor traductora de Llull no fue única: fueron muchos los traductores medievales que contribuyeron a expandir la religión cristiana y a forjar las lenguas vernáculas europeas (Delisle y Woodsworth 2005: 143).

En las tierras de lengua catalana, la práctica autotraductora tiene una larga tradición. Tras los innumerables trabajos de Llull, cabe destacar las autotraducciones de Berenguer Eimeric (ca.1290-1365) o de Arnau de Vilanova (1238 ó 1240-1331), aunque las más conocidas y estudiadas fueron las de Enrique de Aragón, marqués de Villena (1384-1434), quien tradujo al castellano una obra escrita originalmente en catalán sobre un mito clásico, Dotze treballs d'Hèrcules (1417), que tituló Libro de los doce trabajos de Hércules (1482). Cuenta Santoyo que Villena se consideraba "dueño de uno y otro texto, libre por tanto para actuar sobre uno u otro como mejor lo estima[ba]" (2010: 368). En otras palabras, Villena se tomó la libertad de componer una recreación literaria en su autotraducción al castellano a la que añadió y suprimió distintos parágrafos e ideas del original.

\footnotetext{
1 Quizás Mendoza hablaba a partir de la propia experiencia. El novelista catalán es autor de una autotraducción. Se trata de la obra teatral Restauració (1990), escrita originalmente en catalán y autotraducida al castellano. Esta es la única autotraducción que se le conoce. Mendoza ha publicado quince novelas, varios libros de relatos y otros tantos ensayos, siempre en lengua castellana.
} 
Cabe mencionar que estos autores no fueron los únicos que se autotradujeron en su época, y que en los siglos XVı y XVII hubo una eclosión de las autotraducciones, y no solamente en la Península Ibérica, que con diversas frecuencias ha llegado hasta nuestros días. Recordemos que autores modernos tan internacionales como Samuel Beckett (1906-1989) o Vladimir Nabokov (Vladímir Vladímirovitx Nabókov [1899-1977]) ejercieron habitualmente la autotraducción, al lado de muchos otros que quizás no sean tan conocidos. En el ámbito estrictamente catalán y contemporáneo, encontramos un buen número de autores que, en algún momento de su vida literaria, han ejercido la autotraducción, como Quim Monzó (1952), Carme Riera (1948), Valentí Puig (1948), Baltasar Porcel (19382009) o Joan Francesc Mira (1939). Todos estos autores escriben sus obras de ficción en catalán y, a menudo, las trasladan ellos mismos al castellano. Son por tanto escritores bilingües de expresión literaria catalana que deciden asumir la traducción al castellano de sus propias obras. Se trata de autores que escriben en su lengua materna pero que, habiendo sido escolarizados en castellano, o en ambas lenguas, deciden autotraducirse. A este respecto, Rainier Grutman afirma que las situaciones sociopolíticas y socioculturales son fundamentales para que surjan autotraducciones, porque:

... desgraciadamente [hay] diferencias apreciables entre las lenguas del mundo en términos de mercado y de valor de intercambio (ique es otra cosa muy distinta del valor intrínseco!). No es de extrañar, pues, que hayan dejado huellas en la forma particular de tráfico lingüístico-cultural que es la traducción: hay lenguas de y a las que se ha traducido mucho como hay lenguas de y a las que se sigue traduciendo mucho menos. Asimismo, es importante recordar que estas diferencias pueden (aunque no deben) influir sobre la decisión de un escritor bilingüe de traducirse o no. (Grutman 2011: 79)

En los contextos bilingües y/o biliterarios, las autotraducciones son un fenómeno traductológico mucho más habitual que en los contextos monolingües. Su proliferación en el ámbito ibérico ha crecido enormemente en las últimas décadas, hasta el punto que Christopher Whyte (2002: 65) declaraba que "Spain since the death of Franco is perhaps richer than other European nations in instances of self-translation".

Efectivamente, desde el advenimiento de la democracia en España, han sido numerosos los autores catalanes (y también gallegos, y en menor número vascos) que han llevado a cabo, y por diversos motivos, las traducciones de sus propias obras. ${ }^{2}$ Hay que tener en cuenta que estamos ante un grupo de autores que escriben literatura -especialmente narradores y poetas- en sus lenguas maternas pero que, sobre todo si nacieron a partir de mediados de los años 70, fueron escolarizados en castellano, o en ambas lenguas -en su lengua materna y en castellano-, con lo cual la tarea de traducirse resulta más sencilla. Estamos ha-

\footnotetext{
2 Julio César Santoyo, que ha dedicado varios trabajos al ámbito de las autotraducciones ibéricas recientes, catalogó más de 200 escritores cuyas obras han sido autotraducidas en España hasta finales del siglo xx. Véase a este respecto Santoyo (2006: 24).
} 
blando de traducciones unidireccionales: se trata únicamente de obras literarias originales en catalán, gallego o vasco, que sus autores traducen al castellano.

\section{Algunos motivos de la autotraducción}

Cabría preguntarse qué razones impulsan a los traductores a autotraducirse. Hay quien afirma sin tapujos que existen tantos motivos como autotraductores (Ramis 2008: 18), aunque quizás se podría conmutar el término "autotraductores" por "autotraducciones". La profesora de traducción Luisa Cotoner que ha traducido varias obras de Carme Riera al castellano ${ }^{3}$ y ha estudiado las autotraducciones de la novelista mallorquina, advierte que en ciertos casos el autor no puede "consentir que otro u otra se inmiscuyan en lo que considera una nueva recreación de su obra" (2004: 159). En realidad, la situación del Estado español parece garantizar un alto nivel de conocimiento de ambas lenguas en los territorios bilingües, razón por la cual no debería sorprendernos el uso continuado de la autotraducción.

Ahora bien, los motivos y las circunstancias para ejecutar las autotraducciones pueden variar de unas a otras aunque haya algunos móviles especialmente recurrentes en la actualidad. Centrándonos en las culturas literarias ibéricas y en el tiempo más reciente, se observan cuatro categorías principales. En primer lugar, se podría hablar de "rapidez y economía": un autor "bilingüe" conocedor de un léxico específico para el estudio del cual ha invertido mucho tiempo puede traducir un texto propio con mayor celeridad que un traductor que desconoce dicho léxico o que no está acostumbrado a manejarlo. ${ }^{4}$ En segundo lugar, encontramos aquellos autotraductores que traducen sus obras bajo una cierta psicosis autorial: están convencidos de que nadie mejor que ellos conocen los entresijos de sus obras, lo cual suele ocurrir cuando el autor/traductor está decepcionado por la calidad de las anteriores traducciones de sus libros (Arnau i Segarra 2016). El autor emplea su poder creativo y su dominio, no quiere compartirlos con el traductor, y se nos muestra de esta manera como "un autotraductor desconfiado, que ejerce su conocimiento del original en forma de poder, que, por así decirlo, "menosprecia" la intervención profesional de los traductores, y que desea ejercer control absoluto sobre el original y la traducción" (Parcerisas 2011: 166).

En tercer lugar, se podría hacer referencia a una práctica de "exhibicionisme lingüístic, entès com a demostració innecessària del coneixement de l'altra llengua" (Ramis 2008: 19), un motivo que se puede producir especialmente en autores nacidos en territorios lingüísticos distintos a aquellos donde escriben, y aún más cuando estos son territorios bilingües. En el caso catalán, encontramos autores de origen extranjero residentes en Cataluña que han aprendido las dos lenguas oficiales del territorio donde viven, pero que acostumbran a utilizar solo

\footnotetext{
3 Las traducciones que ha realizado Luisa Cotoner de libros narrativa de Carme Riera han sido publicadas como sigue: Una primavera para Doménico Guarini. Barcelona, Montesinos, 1981; Te dejo el mar. Madrid, Espasa-Calpe, 1991; Llamaradas de luz. Madrid, Anaya, 1991.

${ }^{4}$ Me refiero especialmente a traducciones especializadas: textos jurídicos, de biología, química, medicina, farmacia u otros que incluyan un léxico específico.
} 
una de ellas para la escritura literaria. Algunos de estos autores surgidos de la inmigración sienten la "necesidad" de demostrar que dominan las dos lenguas, y escriben en ambas, o incluso se autotraducen. ${ }^{5}$

Otro motivo sería, evidentemente, el económico, aunque ello dependa mucho del mercado laboral. La traducción es una actividad remunerada que implica una faceta profesional complementaria para los escritores. Ya en el año 2003, Antonio Bueno afirmaba tajantemente en un artículo sobre la autotraducción que uno decide traducirse únicamente por el dinero (Bueno 2003). Si bien no puedo compartir dicha declaración de intenciones, hay que tener en cuenta que el autotraductor cobra los derechos de autor y de traductor (Arnau i Segarra 2016).

En general, pensamos que los autores catalanes que deciden autotraducirse lo hacen motivados por una amalgama diversa y cambiante de todos los argumentos expuestos, y quizás otros más. El escritor catalán que decide autotraducirse es consciente de su superioridad lingüística, pero también, como afirma Dasilva, que "la negativa de un autor [bilingüe catalán, gallego o vasco] a autotraducirse puede considerarse como un gesto de reivindicación de su propia identidad cultural" (2009: 147). En este contexto, García de Toro afirma que la "elevada competencia lingüística condiciona sin duda la traducción entre las lenguas del territorio" (2009: 54). Efectivamente, tanto la traducción como la autotraducción de textos "en un contexto de convivencia de lenguas [dificulta] sostener que una de las dos lenguas pueda ser considerada lengua extranjera. Consecuentemente, al traductor profesional [y al autotraductor] se le supone una competencia bidireccional con más frecuencia que a traductores de otras parejas lingüísticas" (García de Toro 2009: 59). La autotraducción es pues una actividad común en situaciones de lenguas en contacto.

\section{Sobre las autotraducciones de autores CATALANes}

El interés por la autotraductología es un fenómeno reciente en el campo de los estudios literarios. A principios del milenio Rainier Grutman (2000) asociaba la ausencia de trabajos sobre la autotraducción a la tendencia de enmarcarla exclusivamente en el campo del bilingüismo y no en el de los estudios literarios o traductológicos. Sin embargo, tan solo siete años más tarde, el mismo Grutman (2007) se congratulaba del reconocimiento de la autotraducción como disciplina objeto de estudio. La situación había cambiado, especialmente gracias a numerosos estudios teóricos, pero en el Estado español, el número de estudios que tiende a relacionar la autotraducción en las zonas periféricas con el bilingüismo sigue siendo muy elevado.

\footnotetext{
${ }^{5}$ Nos referimos a autores nacidos en Marruecos y emigrados a Cataluña en su infancia, como Najat El Hachmi, Laila Karrouch o Saïd El Kadaoui Moussaoui. Son narradores que escriben preferentemente en catalán, aunque también hayan publicado artículos de prensa en castellano, y en algún caso se han autotraducido. También encontramos escritoras-traductoras catalanas de origen checo como Monika Zgustová, que escribe en tres lenguas, o autores ingleses como Matthew Tree, que escribe narrativa en inglés y en catalán, tanto ficción como ensayística, y, esporádicamente, publica artículos en castellano en la prensa diaria.
} 
En Cataluña contamos con diversos especialistas que han realizado grandes aportaciones al estudio de la autotraducción, como Helena Tanqueiro (1999; 2000; 2007; 2011) o Francesc Parcerisas (2010; 2011), investigadores vinculados de alguna forma a la Universitat Autònoma de Barcelona, en cuya Facultat de Traducció i Interpretació se han desarrollado diversos grupos de investigación sobre la autotraducción. Sin embargo, cabe reconocer, como ya afirmaba Grutman (2000), que muchos estudios sobre la autotraducción catalana siguen estando vinculados al bilingüismo autorial. García de Toro ya señala que son autores "especialmente de textos literarios, y con un elevado grado de bilingüismo [quienes] deciden traducir sus propias obras" (2009: 61-62). En otras palabras, el bilingüismo sigue siendo un motivo primordial a la hora de realizar autotraducciones en las tierras catalanas.

En su ya emblemático L'escriptor català i el problema de la llengua (1975), Francesc Vallverdú proclamaba la coexistencia de distintos grupos de escritores bilingües en Cataluña:
a) escriptor que escriu alternadament en castellà i en català;
b) escriptor catalanoparlant que escriu en castellà;
c) escriptor familiarment bilingüe, o castellanoparlant, que escriu alternada- ment en català;
d) escriptor que en dues èpoques successives ha escrit en català i en castellà, pero no pas simultàniament;
e) escriptor que escriu en català i se serveix ocasionalment (o permanentment) del castellà en un nivell no literari, purament instrumental (llengua escrita o vulgar). (Vallverdú 1975: 73-74).

Segun Vallverdú, solo podemos hablar de bilingüismo literario en los casos a y d (1975: 74), es decir, cuando el escritor escribe de forma sucesiva en ambas lenguas, o cuando ha cambiado en dos épocas sucesivas de una lengua a otra. ${ }^{6}$ En la actualidad, al igual que en los años 70, son mayormente los autores que escriben en catalán los que traducen sus obras al castellano. Es lo que suele llamarse "traducciones dominantes": aquellas que son realizadas de la lengua minoritaria (o minorizada), la catalana, a la normalizada, el castellano. No son frecuentes las traducciones en el sentido inverso por entenderse que los consumidores de esas poblaciones son bilingües. En estas cuatro últimas décadas ha aparecido un nuevo fenómeno que requiere, según nuestro parecer, la redefinición del concepto de escritor bilingüe catalán o, al menos, el añadido de una nueva categoría. Nos referimos a la aparición de la literatura exófona catalana, fruto de la emigración extranjera surgida a partir de los años 80. Cabría preguntarse dónde ubicaría Vallverdú actualmente escritores catalanes como Najat el

\footnotetext{
6 Pensemos concretamente en autores que debutaron en lengua castellana, y más tarde se pasaron decididamente a la catalana. Son especialmente aquellos que, debido a las prohibiciones franquistas, no pudieron aprender a escribir su lengua materna, el catalán, hasta la edad adulta, y por propio convencimiento. El escritor y periodista Antoni Serra (Sóller, 1936), sería un buen ejemplo. Tras una vida bohemia, publicó una trilogía novelística en castellano, pero a partir de 1972 toda su obra literaria de ficción se editó en lengua catalana. Y así hasta nuestros días.
} 
Hachmi (1979), Laila Karrouch (1977) o Said El Kadaoui Moussaoui (1975), todos ellos nacidos cerca de Nador, en Marruecos. Son autores de lengua materna amazigh que emigraron durante la infancia a Cataluña y escriben literatura de ficción en catalán, e incluso en algunos casos, se autotraducen al castellano. Otro caso similar sería la joven escritora Lucia Pietrelli (1984), nacida en Italia pero residente en Mallorca desde hace unos cinco años (después de haber vivido en Madrid y en Barcelona). Pietrelli está confeccionando en Mallorca una sólida obra poética y narrativa en catalán (sus primeros poemas fueron en italiano, y más tarde en castellano), y ha obtenido varios prestigiosos premios literarios del mundo editorial catalán en los últimos seis meses. Creemos no exagerar al afirmar que la necesidad llevaría a Vallverdú a crear una nueva categoría, la del escritor exófono catalán que escribe literatura en catalán, ensayo y artículos periodísticos en catalán y castellano, y, en algunos casos, se autotraduce al castellano.

Así pues, estamos ante lo que Xose Manuel Dasilva (2009) denomina "autotraducciones diglósicas", es decir, autotraducciones fruto del dominio de una lengua sobre otra. Dasilva ofrece una tipología de la autotraducción de los autores periféricos gallegos (2009: 152) que se puede aplicar perfectamente al caso catalán. De este modo, la autotraducción desde una lengua minorizada como el catalán a una lengua normalizada como el castellano reúne una serie de características que la alejarían del bilingüismo tan pregonado, cuando en realidad estamos ante una diglosia. ${ }^{7}$ Así, cabe destacar que a menudo se oculta en los créditos de la autotraducción que el libro que el lector está leyendo es una versión realizada desde otra lengua, e incluso por el mismo autor. Andreu van Hooft acusa al ISBN de "distorsionar la imagen del polisistema interliterario en España" (2004: 316-317). En este contexto, Even-Zohar advierte del hecho de que en las literaturas periféricas, que tienden a coincidir con las literaturas de las naciones más pequeñas, se han establecido relaciones jerárquicas entre ellas. Y es que:

... no solo el estatus socio-literario de la traducción depende de su posición dentro del polisistema; la práctica misma de la traducción está también fuertemente subordinada a dicha posición. E incluso la pregunta de qué es una obra traducida no puede ser respondida a priori en términos de una situación idealizada, a-histórica y fuera de contexto: tiene que cimentarse en el ámbito de las operaciones que gobiernan el polisistema. Desde este punto de vista ya no se puede considerar la traducción como un fenómeno de naturaleza y límites definidos de una vez por todas, sino como una actividad que depende de las relaciones establecidas dentro de un determinado sistema cultural. (Even-Zohar 2007: 96)

La traducción de textos desde las literaturas periféricas a las que jerárquicamente se suponen, nos guste o no, sobre ellas, responde también a la valoración establecida entre lenguas dominantes y lenguas minorizadas. De este

\footnotetext{
7 Entendemos la diglosia como la situación sociolingüística en que conviven dos lenguas, y donde una goza de mayor prestigio y reconocimiento social que la otra. Este concepto lingüístico puede aplicarse también, como veremos, a las traducciones y las autotraducciones literarias.
} 
modo, y volviendo al ejemplo aludido por van Hooft sobre el ISBN, podemos afirmar que son numerosos los casos en que una autotraduccion del catalán al castellano ha sufrido una distorsión. Uno de los casos más radicales es el de la versión castellana de la obra autobiográfica de Laila Karrouch titulada De Nador a Vic (2004), que obtuvo el Premi Columna Jove de ese mismo año. ${ }^{8}$ De Nador a Vic se publicó en castellano con el título Laila (2010), con grandes modificaciones que ocultan su origen catalán, y ni en los créditos ni en el menor de los peritextos aparece el nombre del o de la traductora. Del mismo modo que le sucedió a César Domínguez (2013: 108), ni la editorial Columna, editora de De Nador a Vic, ni la editorial Oxford, editora de Laila, han contestado a mis mensajes electrónicos en los que me interesaba por distintos aspectos relacionados con la autoría de la traducción de dicha obra y su recepción en los medios de comunicación. A pesar de ello, y corriendo el riesgo de equivocarnos, se desprende de la consulta de los peritextos de Laila que dicha narración es la (auto)traduccion llevada a cabo por Laila Karrouch de De Nador a Vic (Arnau i Segarra 2016). Estamos, sin duda, ante una (auto)traducción opaca. ${ }^{9}$

Siguiendo con las características que Dasilva (2009: 152-153) asigna a las autotraducciones diglósicas, otro síntoma que las conforma sería el hecho de que salgan al mercado el original y su autotraducción simultáneamente, o con muy poca distancia temporal. En este ámbito destaca una de las autoras catalanas más prolíficas en autotraducciones, Carme Riera, quien ha publicado, entre otras, las versiones castellanas de diversas obras suyas, entre las que encontramos Contra l'amor en companyia i altres relats (1991) con el título Contra el amor en compañía y otros relatos (1991); la novela histórica por excelencia Dins el darrer blau (1994) autotraducida como En el último azul (1996); la novela folletinesca Cap al cel obert (2000) en versión propia como Por el cielo y más allá (2001) o la novela satírica Amb ulls americans (2009) convertida en Con ojos americanos (2009). Aunque más adelante nos referiremos de nuevo a Carme Riera, quizás tendríamos que añadir aquí que Carme Riera es catedrática universitaria de Filología Hispánica y miembro electo de la Real Academia de la Lengua Española desde 2013.

Otra autora que también se autotraduce es Maria de la Pau Janer. Desde que quedó finalista en el Premio Planeta de 2002, Janer ha publicado la mayor parte de sus obras casi simultáneamente en catalán y castellano. Así, por ejemplo, Pasiones romanas (2005) y Passions romanes (2006), aunque, según la propia autora, la primera versión fue la catalana, si bien se publicó un año más tarde; o Cartes que sempre he esperat (2010) y Cartas que siempre esperé (2010).

\footnotetext{
8 Laila Karrouch es autora de otra obra de signo autobiográfico, Petjades de Nador (2013), cuya traducción literal sería Huellas de Nador. También ha publicado Un meravellós llibre de contes àrabs per a nens $i$ nenes de tot el món (2006) [Un maravilloso libro de cuentos árabes para niños y niñas de todo el mundo], en que la autora se inspira en la tradición oral bereber de su cultura materna, y Quan a l'Isma se li van creuar els cables (2015).

9 Sobre los conceptos de "autotraducción opaca" y "autotraducción transparente" véase Dasilva (2011).
} 
La tercera característica diglósica que cita Dasilva (2009: 152) es la direccionalidad de las autotraducciones, es decir, que la mayor parte se trasladen de una lengua minorizada -en el caso que nos ocupa sería el catalán- a una lengua normalizada, como sería el castellano. Y bien es verdad que, si exceptuamos el caso de Maria de la Pau Janer con sus dos premios Planeta, que nunca sabremos con seguridad si primero fue la versión catalana o la castellana o, como a veces ha declarado, escribe las dos a la vez (!), lo cierto es que desconocemos por completo la existencia de autotraducciones del castellano al catalán. Según Dasilva (2009: 152) son inexistentes, aunque sí que podemos encontrar algunas traducciones del castellano al catalán de obras noveladas por autores catalanes que escriben en castellano, ya que, añadimos nosotros, existe un público lector catalán en aumento que gusta de leer versiones catalanas de obras castellanas, especialmente si son de autores catalanes y están ambientadas en los territorios de lengua catalana. Podemos citar la archifamosa Soldados de Salamina (2001), de Javier Cercas, traducida al catalán por Ponç Puigdeval en Soldats de Salamina (2003); o La sombra del viento (2001) de Carlos Ruiz Zafón, traducida por Josep Pelfort como L'ombra del vent (2002); o La catedral del mar (2006), de Ildefonso Falcones, traducida como L'ésglesia del mar (2006) por Carles Urritz.

Volviendo al carácter diglósico de las autotraducciones, podríamos añadir siguiendo a Dasilva (2009: 153) que otra peculiaridad se centra en el hecho de que los autores que se traducen a sí mismos no acostumbran a traducir la obra de otros escritores. Por lo tanto, su práctica traductora se reduce al ejercicio de la traducción de sus propias obras, a la autotraducción, y, siempre, en una dirección exclusiva determinada, de una única lengua A original (catalán) a una sola lengua B meta (castellano).

De acuerdo con Anton Popovič (2006: 40) la autotraducción no puede ser considerada una variante del prototexto. Como resultado del bilingüismo autorial, el texto resultante es un nuevo canal comunicativo. Así, el ejercicio de la autotraducción se convierte en una práctica manifiesta de reescritura creativa en otra lengua. Brian Fitch (1988: 130), analizando las autotraducciones de Samuel Beckett, concluye afirmando que el texto autotraducido se convierte en una creación artística autónoma que no tiene porqué suponer un reflejo directo del prototexto. En realidad, los cometidos del autotraductor son tan complejos que a menudo los propios autotraductores prefieren hablar de nuevas versiones literarias en lugar de textos autotraducidos. Carme Riera es probablemente la autora catalana contemporánea que más ha reflexionado sobre la autotraducción, una autotraducción privilegiada si tenemos en cuenta que Riera ha escrito su obra literaria completa en su lengua materna, el catalán, pero se formó en castellano en tiempos de la dictadura. En los años 70 estudió Filología Hispánica en la Universitat de Barcelona; se doctoró sobre la Escuela Poética de Barcelona y ha ejercido durante más de treinta años como profesora de literatura española en la Universitat Autònoma de Barcelona. Carme Riera, a quien la experiencia de traducir su novela Dins el darrer blau al castellano la dejó "completament esgotada" (Riera 1997), manifiesta un gran pesimismo cuando afirma que "La traducció és sempre una mancança. Per molt bona que sigui, per molt que inten- 
ti conservar el color, el gust, l'olor de l'original, el resultat mai no serà el mateix, encara que sigui bo serà tota una altra cosa" (Riera 1997). Pero a pesar de ello, ha autotraducido algunas de sus obras. La autotraducción para Riera significa hacer una nueva versión del texto, reescribirlo. Y, a pesar de que autotraducirse le implique un esfuerzo casi sobrehumano, la autora expone su método óptimo de autotraducción, es decir, una autotraducción simultánea:

Per mi, l'ideal seria poder treballar com vaig fer-ho amb la novel·la Qüestió d'amor propi. Quan l'estava escrivint l'anava traduint a la vegada; això em donava un punt de vista diferent per anar observant com funcionava en l'altra llengua i esmenar els aspectes que no em semblaven pertinents, perquè em convertia en una lectora crítica del meu propi text, molt més distanciada que quan llegia en la meva pròpia llengua després d'escriure, per anar corregint. El filtre que suposava passar per un altre idioma em feia, segurament, objectivar molt més, em convertia en una receptora i no en una emissora del text en qüestió; una receptora que alhora tornava a emetre el discurs textual des d'una altra perspectiva, reescrivint-lo després de dialogar amb el text molta més estona ja que, per mi, la recreació al castellà em resultava més difícil que l'elaboració en català. (Riera 1997)

Pero el método ideal deja de serlo cuando se quiere avanzar con una cierta rapidez. Hablando del proceso simbiótico entre escritura y autotraducción de lo que se convertiría más tarde en la novela Cap al cel obert, Carme Riera afirmaba que:

... ni amb Joc de miralls ni en Dins el darrer blau, vaig poder fer el mateix, no disposava de temps per crear i recrear alhora i vaig traduir quan la versió original ja circulava impresa feia bastant de temps. Ara estic escrivint una altra novel.la també històrica que succeeix a Cuba a finals del segle passat i he intentat reescriure-la en castellà encara que, evidentment, no la tinc acabada, però l'exercici m'ha resultat tan dificultós que l'he abandonat, em relentia massa l'execució de la versió original catalana; per això crec que, com els deia abans, no tornaré a fer versions castellanes. (Riera 1997)

Riera, a pesar de sus palabras de rechazo a proseguir con las autotraducciones, pronunciadas en 1997, ha continuado elaborando nuevas versiones castellanas de sus libros, y desde aquella fecha hasta el día de hoy contamos con al menos diez autotraducciones más, como por ejemplo Tiempo de espera [Temps d'una espera] de 1998, La mitad del alma [La meitat de l'ànima], de 2005, El verano del inglés [L'estiu de l'anglès] de 2006 o Naturaleza casi muerta [Natura quasi morta] de 2012.

Una de las características de las autotraducciones de Carme Riera es que durante el proceso tiene en mente a los destinatarios de sus versiones castellanas. La autora no solamente traduce sus propios textos sino que, como excelente conocedora de las dos culturas, la catalana y la española, adapta, modifica y manipula para conseguir el efecto deseado. Porque: 
Lo mismo que resulta elemental señalar la existencia de variaciones culturales entre lenguas de ámbito espacial distinto, también lo es insistir en la diferencia territorial que existe entre el castellano y el catalán, que conlleva la pertenencia a tradiciones culturales asimismo distintas, aunque sea dentro de un mismo Estado. Sin embargo, hay que tener en cuenta otro aspecto menos evidente: las variaciones culturales se producen asimismo en el orden temporal, sobre todo, cuando se trata de trasladar una figura tan escurridiza como la ironía (Cotoner 2011: 12)

Riera utiliza diversos recursos para trasladar los conceptos culturales de una lengua a otra, con una libertad autorial de la cual carecería un traductor ajeno al texto original. Así, por ejemplo, en la versión castellana del relato "La novel.la experimental" de Contra l'amor en companyia $i$ altres relats, algunos nombres de personajes se adaptan al lector destinatario: el poeta catalán Salvador Espriu se convierte en el escritor español Miguel de Cervantes, y el Premi Prudenci Bertrana de Girona se transforma en el Planeta, ambos muy bien dotados económicamente. En otros casos, Riera añade datos a acontecimientos, como una larga descripción de la "diada de Sant Jordi" para el público lector de La mitad del alma, novela que reúne un número muy elevado de recursos autotraductológicos rierianos. Uno de los más singulares es la conservación en catalán de una larga frase de Josefa, la cocinera de los padres de la protagonista, un personaje entrañable que de pequeña le decía: "Ja ho veus, estimada dolça, colflorieta meva, pastanagó, cebeta tendra, glop de vi dolç... Tu no en tindràs pas, de tifus, no, reina meva, tu no prendràs mal" (Riera 2004: 51). En la versión castellana, Riera mantiene estas cariñosas palabras pero incluye una nota a pie de página con la traducción casi literal: "Ya lo verás, queridita mía, coliflorcita mía, zanahorita, cebollita tierna, sorbito de vino dulce, tú no te pondrás enferma, te lo aseguro, tú no" (Riera 2005: 48).

La autotraductora opta a menudo por cambiar los nombres de personajes históricos, de ciudades o de títulos de libros, eligiendo aquellos que mejor podrían corresponder a la cultura receptora. Con ello, Riera se toma unas libertades que ningún traductor profesional podría asumir sin el consentimiento expreso del autor del texto original. La independencia con la que puede trabajar un autotraductor modificando o manipulando los conceptos culturales representa el procedimiento más radical de la autotraducción.

\section{A MODO DE CONCLUSIÓN}

La autotraducción catalana es un fenómeno que se remonta a la Edad Media y que ha evolucionado y cambiado según los tiempos. En la actualidad son muchos los escritores catalanes que, por motivos diversos, deciden asumir la autotraducción de sus textos. Son autores de lengua materna catalana que, en la gran mayoría de los casos, crecieron y se educaron durante el franquismo y, por lo tanto, tuvieron una escolarización exclusivamente en castellano. Dichas autotraducciones son unidireccionales y pueden denominarse diglósicas debido a la situación sociolingüística del territorio en el que la lengua dominante continúa 
siendo el castellano. Francesc Parcerisas les otorga una autoría tan alta como al primer original catalán, ya que los autores de las versiones castellanas actúan desde una posición de poder excepcional (2010: 215). En este sentido, el binomio que representa la relación entre lenguas en contacto y autotraducción cristaliza un fenómeno tan complejo como es el de la reescritura textual. La frontera entre lo que sería la autotraducción y la versión se diluye y podemos afirmar que cada autotraducción responde no solamente a la competencia lingüística y la capacidad creativa de su autor, sino también a toda una serie de relaciones lingüísticas y culturales de carácter jerárquico que confluyen en cada obra traducida.

\section{OBRAS CITADAS}

Arnau i Segarra, Pilar (2016): "Laila o la deliberada invisibilidad de la cultura catalana". Inédito [en curso de edición en Frankfurt/Madrid, Vervuert/Iberoamericana].

Bueno, Antonio (2003): "Le concept d'autotraduction". En: Michel Ballard y Ahmed Elkaladi (eds.): Traductologie, linguistique et traduction. Arras, Artois Presses Universitaires, pp. $10-25$.

Cotoner, Luisa (2004): "Ética y estética de la autotraducción: Una cala en las versiones al castellano de Josep Pla, Joan Perucho y Carme Riera". En: Emilio Ortega Arjonilla (ed.): Panorama actual de la investigación en traducción e interpretación, vol. III. Granada, Atrio, pp. 159-167.

— (2011): "Variación cultural, técnicas y procedimientos estilísticos a propósito de las autotraducciones al castellano de Carme Riera", Tejuelo, n. 10 , pp. 10-28.

Dasilva, Xosé Manuel (2009): "Autotraducirse en Galicia: ¿bilingüismo o diglosia?", Quaderns. Revista de Traducció, n. ${ }^{\circ}$ 16, pp. 143-156.

— (2011): "La autotraducción transparente y la autotraducción opaca". En: Xosé Manuel Dasilva y Helena Tanqueiro (eds.): Aproximaciones a la autotraducción. Vigo, Academia del Hispanismo, pp. 45-67.

Delisle, Jean, y Woodsworth, Judith (eds.) (2005): Los traductores en la historia. Medellín, Grupo de Investigación en Traductología / Universidad de Antioquía.

Domínguez, César (2013): "Literatures in Spain: European Literature, World-Literature, World-Literature?". En: Santiago Pérez Isasi y Ángela Fernandes (eds.): Looking at Iberia. A Comparative European Perspective. Berna, Peter Lang, pp. 99-119.

Even-Zohar, Itamar (2007): Polisistemas de cultura. (Un libro electrónico provisorio). Disponible en <http://www.tau.ac.il/ itamarez/works/papers/trabajos/polisistemas_de_ cultura2007.pdf> [última visita: 20.05.2016].

Fitch, Brian T. (1988): Beckett and Babel: An Investigation into the Status of the Bilingual Work. Toronto, University of Toronto, pp. 132-133.

García de Toro, Cristina (2009): La traducción entre lenguas en contacto. Catalán y Español. Berna, Peter Lang.

Grutman, Rainier (2000): "Auto-translation". En: M. Bake (ed.): Routledge Encycopedia of Translation Studies. Londres / Nueva York, Routledge, pp. 17-20.

_ (2007): "L'autotraduction: dilemne social et entre-deux textuel", Atelier de traduction, n. ${ }^{\circ}$, pp. 193-202. 
(2009): "La autotraducción en la galaxia de las lenguas", Quaderns. Revista de Traducció, n. 16, pp. 123-134.

(2011): "Diglosia y autotraducción 'vertical' (en y fuera de España)". En: Xosé Manuel Dasilva y Helena Tanqueiro (eds.): Aproximaciones a la autotraducción. Vigo, Academia del Hispanismo, pp. 69-91.

Hooft Comajuncosas, Andreu van (2004): “¿Un espacio intercultural en España? El polisistema interliterario en el estado español partir de las traducciones de las obras pertenecientes a los sistemas literarios vasco, galego, catalán y español (1999-2003)". En: Anxo González Abuin et al. (eds.): Bases metodolóxicas para unha historia comparada das literaturas da península Ibérica. Santiago de Compostela, Servicio de Publicaciones de la Universidad de Santiago de Compostela, pp. 313-333.

Parcerisas, Francesc (2010): "La difusió de la literatura catalana en el món editorial espanyol del segle xx". En: Enric Gallén, Francisco Lafarga y Luis Pegenaute (eds.): Traducción y autotraducción en las literaturas ibéricas. Berna, Peter Lang (Relaciones literarias en el ámbito hispánico: traducción, literatura y cultura vol. 2), pp. 193-220.

— (2011): "Autotraducción y 'Lógica moral': unos ejemplos autobiográficos". En: Xosé Manuel Dasilva y Helena Tanqueiro (eds.): Aproximaciones a la autotraducción. Vigo, Academia del Hispanismo, pp. 165-173.

Popovič, Anton (2006): La scienza della traduzione. Aspetti metodologici. La comunicazione traduttiva. Milán, Hoepli.

Ramis, Josep Miquel (2008): Sebastià Juan Arbó, autotraductor: de Terres de l'Ebre (1932) a Tierras del Ebro (1940). Barcelona, Universitat Pompeu Fabra. Disponible en <https:// repositori.upf.edu/bistream/handle/10230/1262/JMRamis.pdf?sequence=1> [última visita: 16.03.2016].

Recuenco Peñalver, María (2011): "Más allá de la traducción: la autotraducción", TRANS, n. ${ }^{\circ}$ 15, pp. 193-208.

Riera, Carme (1997): "L'autotraducció com a exercici de recreació", V Seminari sobre la Traducció a Catalunya. Quaderns divulgatius, n. ${ }^{\circ} 8$, p. 45-52. Versión en línea: <https:// parles.upf.edu/ca/content/lautotraduccio-com-exercici-de-recreacio> [última visita: 30.01.2016].

_ (2004): La meitat de l'ànima. Barcelona, Proa.

(2005): La mitad del alma. Madrid, Alfaguara.

Santoyo, Julio César (2002): "Traducciones de autor: Una mirada retrospectiva", Quimera, n. ${ }^{\circ} 210$, pp. 27-32.

- (2006): "Blank spaces in the history of Translation". En: Georges Bastin y Paul Bandia, (eds.): Charting the future of translation history. Current discourses and methodology. Ottawa, University of Ottawa Press, pp. 11-43.

(2010): "Autotraducciones intrapeninsulares: motivos históricos, razones actuales". En: Enric Gallén Francisco Lafarga y Luis Pegenaute (eds.): Traducción y autotraducción en las literaturas ibéricas. Berna, Peter Lang Verlag, pp. 365-380.

Tanqueiro, Helena (1999): "Un traductor privilegiado: el autotraductor", Quaderns. Revista de Traducció, n. ${ }^{\circ}$ 3, pp. 19-27.

- (2000): "Self-translation as an extreme case of the authorwork-translator-work dialectic". En: Allisson Beeby et al. (eds): Investigating Translation. Ámsterdam, John Benjamins Publishing Company, pp. 55-64. 
_ (2007): "Der Autor als (Selbst-)Übersetzer kultureller Markierungen in seinen Originalwerken". En: Peter A. Schmitt et al. (eds.): Translationsqualität. Frankfurt, Peter Lang Verlag, pp. 583-590.

— (2011): "Sobre la autotraducción de referentes culturales en el texto original: La autotraducción explícita y la autotraducción in mente". En: Xosé Manuel Dasilva y Helena Tanqueiro (eds.): Aproximaciones a la autotraducción. Vigo, Academia del Hispanismo, pp. 245-259.

Vallerdú, Francesc (1975): L'escriptor català i el problema de la llengua. Barcelona, Edicions 62.

Whyte, Christian (2002): "Against Self-Translation", Translation and Literature, vol. 11, n. ${ }^{0}$, pp. 64-71. 